Check for updates

Cite this: RSC Adv., 2019, 9, 7176

Received 7th January 2019

Accepted 26th February 2019

DOI: $10.1039 / \mathrm{c} 9 \mathrm{ra00141g}$

rsc.li/rsc-advances

\section{High-contrast mechanochromic benzothiadiazole derivatives based on a triphenylamine or a carbazole unit $\uparrow$}

\author{
Yuan-yuan Zhu, Hong-ying Xia, Li-feng Yao, Dan-ping Huang, Jun-yan Song, \\ Hai-feng He, (D)* Liang Shen* and Feng Zhao*
}

Four triphenylamine or carbazole-based benzothiadiazole fluorescent molecules have been successfully synthesized and characterized. Interestingly, the donor-acceptor (D-A) type luminogens 1, 2, 3 and 4 showed different solid-state fluorescence. Furthermore, the four compounds exhibited reversible highcontrast mechanochromism characteristics.
Stimuli-responsive materials receive much attention currently due to their academic importance and potential applications in optoelectronic devices and fluorescent sensors, ${ }^{1-7}$ especially organic smart materials whose solid-state luminescence can be tuned by external stimuli. ${ }^{8-13}$ Mechanochromic fluorescence materials, as a class of smart materials, are also receiving increasing attention. ${ }^{14-20}$ To date, a number of mechanofluorochromic organic molecules have been reported. ${ }^{21-24}$ In contrast, examples of highcontrast mechanochromic luminescence materials are still inadequate. Indeed, many traditional organic materials are aggregation caused quenching (ACQ)-active, and these materials are weakly emissive or nonluminescent in the solid state due to the presence of strong intermolecular electronic interactions in their aggregated state, which promotes the formation of exciplexes and excimers. ${ }^{25-27}$ Obviously, the ACQ effect is unbeneficial to gain highcontrast mechanofluorochromic materials. ${ }^{28-30}$ It is no doubt that mechanochromic molecules with a bright solid-state fluorescence emission are easier to achieve high-contrast mechanofluorochromic phenomenon. Therefore, the corresponding highly emissive smart luminophors have attracted considerable attention. ${ }^{31,32}$

In general, the emission characteristics of mechanochromic luminescence materials depend strongly on their molecular structures and intermolecular interactions. ${ }^{33-35}$ Therefore, it is an effective method for the realization of mechanofluorochromic materials to change the morphological structures by means of external mechanical stimulus. ${ }^{36}$

Benzothiadiazole-based derivatives are regarded as attractive candidates for the organic $\pi$-conjugated fluorescent dyes owing to their strongly electron-withdrawing feature..$^{37-41}$ Meanwhile,

School of Chemistry and Chemical Engineering, Jiangxi Science and Technology Normal University, Nanchang 330013, PR China. E-mail: hehfo427@jxstnu.com.cn; liangshen@jxstnu.com.cn; zhf19752003@163.com

$\dagger$ Electronic supplementary information (ESI) available: Experimental section, and copies of NMR spectra and mass spectra. See DOI: 10.1039/c9ra00141g the benzothiadiazole unit is also advantageous to the construction of donor-acceptor (D-A) type molecules, which have emerged as a significative class of optical materials finding potential value in some areas such as in fluorescent sensors and displays. ${ }^{42,43}$ Motivated by the fact that triphenylamine or carbazole fluorogen has been broadly applied in the field of emissive materials, ${ }^{44,45}$ we attempted to link one triphenylamine or carbazole group to one benzothiadiazole moiety. As a result, we have obtained four $\mathrm{D}-\mathrm{A}$ type fluorescent molecules on the basis of a combination of the electron-donating triphenylamine or carbazole unit and the electron-accepting benzothiadiazole unit (Fig. 1). Compound 1, 2, 3 or 4 contains rotatable aromatic rings, and thus their molecular structures are nonplanar, which is advantageous to the radiative decay in the aggregated state. Indeed, compounds 1, 2, 3 and 4 showed bright solid-state fluorescence with different emission colors. In addition, we found that the D-A type luminogens 1, 2, 3 and 4 applying the triphenylamine or carbazole moiety as an electron donor and the benzothiadiazole moiety as an electron acceptor exhibited various mechanochromic fluorescence characteristics with good reversibility. Furthermore, luminogen 1 showed mechanofluorochromic behavior involving color change from orange to rare red.

To investigate the solid-state fluorescence behaviors of compounds 1, 2, 3 and 4 in detail, the corresponding solid-state
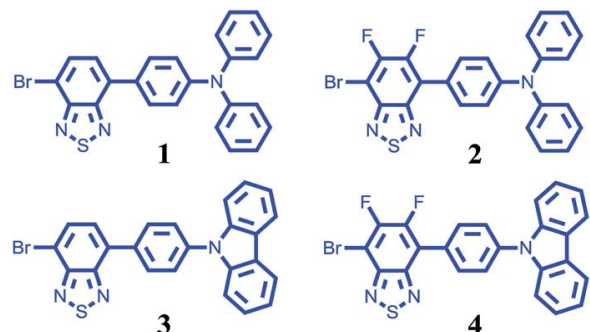

3

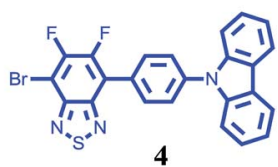

4
Fig. 1 Molecular structures of the compounds 1, 2, 3 and 4. 
emission spectra were studied initially. As shown in Fig. 2, the fluorescence spectrum of triphenylamine-containing benzothiadiazole derivative 1 exhibited one emission band with the $\lambda_{\max }$ at $575 \mathrm{~nm}$, and the fluorescent molecule exhibited strong orange luminescence with the fluorescence quantum yield $(\Phi)$ of $7.13 \%$, and triphenylamine-containing compound 2 exhibited strong yellow luminescence $(\Phi=7.43 \%)$ with the $\lambda_{\max }$ at $567 \mathrm{~nm}$. In contrast, the emission spectrum of carbazole-based benzothiadiazole derivative 3 exhibited one emission band with the $\lambda_{\max }$ at $504 \mathrm{~nm}$, and the luminogen exhibited bright green fluorescence with the quantum yield of $16.10 \%$, and carbazolebased compound 4 also exhibited bright green fluorescence $(\Phi$ $=16.53 \%$ ) with the $\lambda_{\max }$ at $498 \mathrm{~nm}$. Therefore, the photoluminescence (PL) behaviors of compounds 1, 2, 3 and 4 could be adjusted via introducing various fluorogens containing triphenylamine and carbazole. In addition, the fluorescence lifetimes of 1, 2, 3 and 4 were also measured. As shown in Fig. 3, the average lifetime of fluorescent molecule 1 was $0.82 \mathrm{~ns}$, the average lifetime of 2 was 1.56 ns, the average lifetime of 3 was $3.00 \mathrm{~ns}$, and the average lifetime of 4 was $1.41 \mathrm{~ns}$.

Subsequently, the mechanochromic fluorescence characteristics of compounds 1, 2, 3 and 4 were investigated. As shown in Fig. 4, the solid sample of luminogen 1 showed a bright orange fluorescence. Interestingly, the orange luminescence was changed to the red luminescence with the $\lambda_{\max }$ at $593 \mathrm{~nm}$ upon treating with mechanical force stimulus. Furthermore, the initial orange emission could be restored after treatment of the ground compound 1 with fuming dichloromethane for $1 \mathrm{~min}$. Therefore, 1 showed reversible high-contrast mechanofluorochromic behavior with color change from orange to red, which is a relatively rare color conversion among all mechanochromic fluorescence phenomena.

Similarly, as shown in Fig. 5, compound 2 also showed reversible high-contrast mechanochromic fluorescence behavior. Moreover, the reversible mechanochromic fluorescence of 1 or $\mathbf{2}$ could be repeated four times between the orange or yellow and red or orange emissions without obvious changes by alternating grinding and dichloromethane treatments. To date, this mechanochromic luminescence conversion of some reported mechanochromism compounds with superior performance is also repeated three or four times, ${ }^{46-48}$ and thus the reversibility of the mechanochromic fluorescence effect of 1 or 2 is good (Fig. 6). On the other hand, as shown in Fig. 7, when

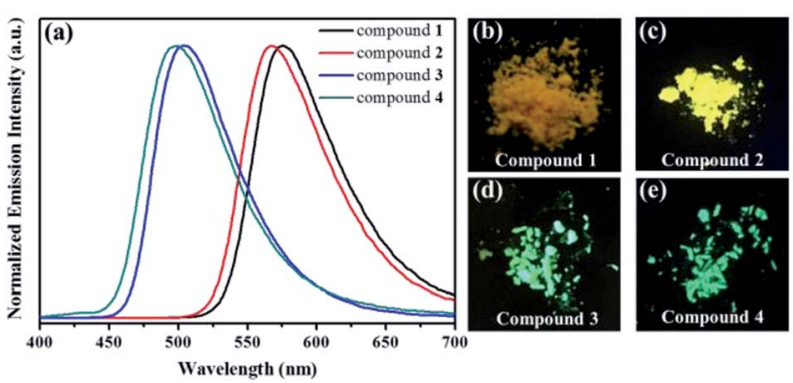

Fig. 2 Solid-state emissive spectra of the compounds 1, 2, 3 and 4, and the related fluorescence images under $365 \mathrm{~nm}$ UV light.
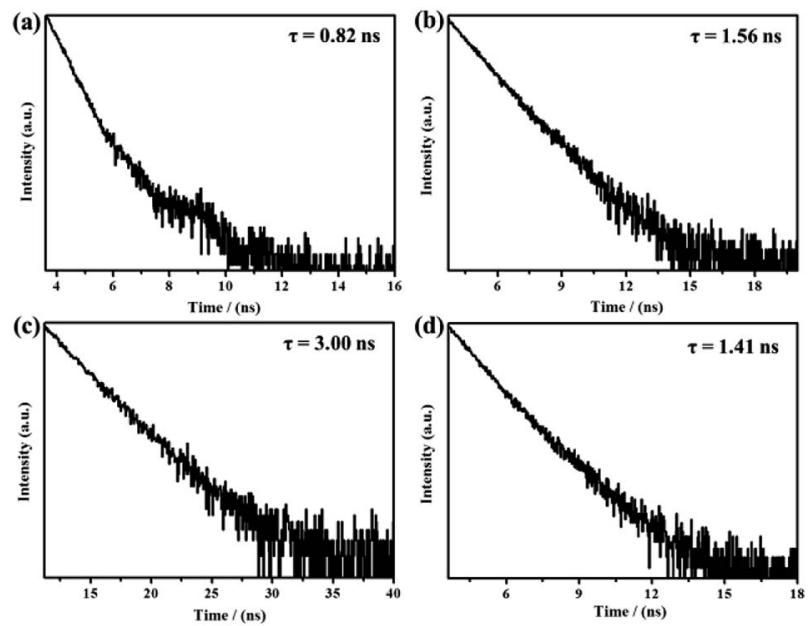

Fig. 3 (a) Time-resolved luminescence $(575 \mathrm{~nm})$ of solid sample 1. Excitation wavelength: $365 \mathrm{~nm}$. (b) Time-resolved luminescence $(567$ $\mathrm{nm}$ ) of solid sample 2. Excitation wavelength: $365 \mathrm{~nm}$. (c) Timeresolved luminescence $(504 \mathrm{~nm})$ of solid sample 3 . Excitation wavelength: $365 \mathrm{~nm}$. (d) Time-resolved luminescence $(498 \mathrm{~nm})$ of solid sample 4. Excitation wavelength: $365 \mathrm{~nm}$.

sample 3 were ground in an agate mortar with a pestle, the green emission was changed to the yellow-green fluorescence with the $\lambda_{\max }$ at $533 \mathrm{~nm}$. Moreover, the yellow-green emission could also revert to the original green emission after a $1 \mathrm{~min}$ treatment of the ground powder with fuming dichloromethane vapor. Furthermore, as shown in Fig. 8, compound 4 also showed similar mechanochromic fluorescence behavior.

As can be seen in Fig. 9, the reversibility of the mechanofluorochromic behavior of compound $\mathbf{3}$ or $\mathbf{4}$ is also excellent. Next, the powder X-ray diffraction (XRD) patterns were studied in order to ensure the morphological characteristics. As can be seen in Fig. 10, the XRD patterns of compound 1 or 2 exhibited a number of sharp reflection peaks, suggesting that the unground compound $\mathbf{1}$ or $\mathbf{2}$ was crystalline in nature. However, the ground powder sample became amorphous, with a lack of sharp diffraction peaks. Therefore, the change in fluorescence of compound 1 or 2 could be attributed to the conversion from a crystalline state to an amorphous state. On the other hand,

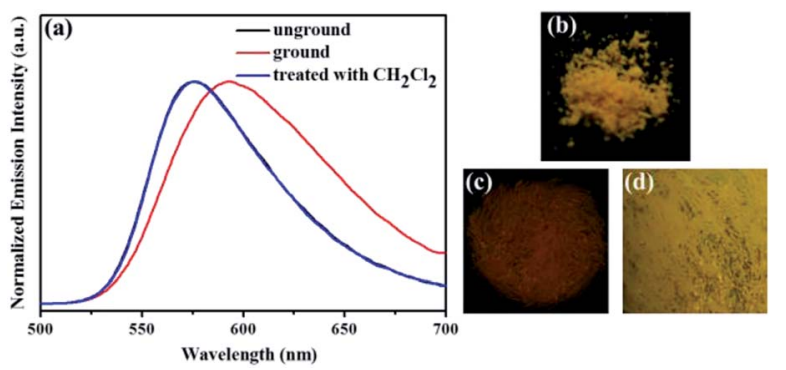

Fig. 4 (a) PL spectra of solid sample 1 at different conditions. Excitation wavelength: $365 \mathrm{~nm}$. (b) Fluorescence image of the unground sample 1 under $365 \mathrm{~nm}$ UV light. (c) Fluorescence image of the ground sample 1 under $365 \mathrm{~nm}$ UV light. (d) Fluorescence image of the ground sample 1 after treatment with dichloromethane under $365 \mathrm{~nm}$ UV light. 


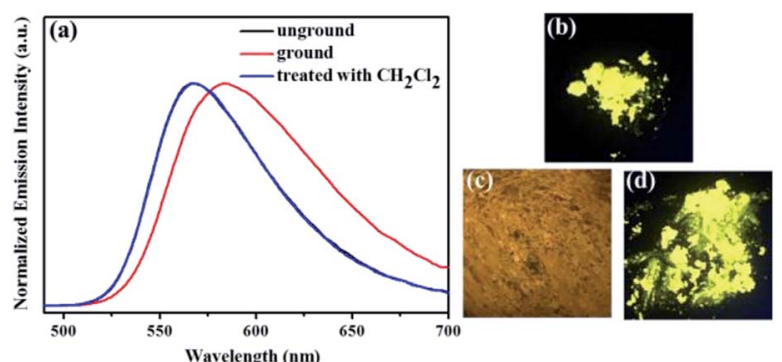

Fig. 5 (a) PL spectra of solid sample 2 at different conditions. Excitation wavelength: $365 \mathrm{~nm}$. (b) Fluorescence image of the unground sample 2 under $365 \mathrm{~nm}$ UV light. (c) Fluorescence image of the ground sample 2 under $365 \mathrm{~nm}$ UV light. (d) Fluorescence image of the ground sample 2 after treatment with dichloromethane under $365 \mathrm{~nm}$ UV light.
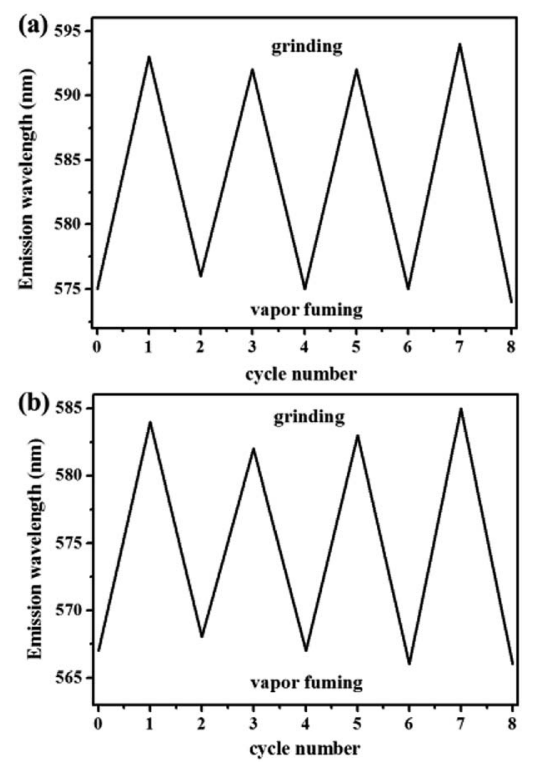

Fig. 6 (a) Repetitive experiment of mechanofluorochromic effect for compound 1. (b) Repetitive experiment of mechanofluorochromic effect for compound 2 .

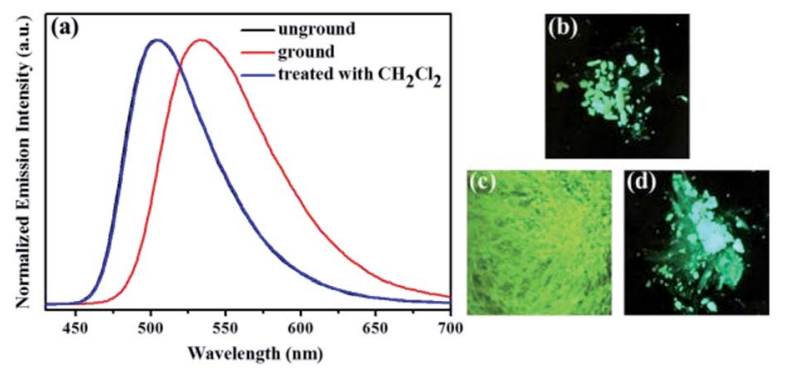

Fig. 7 (a) PL spectra of solid sample 3 at different conditions. Excitation wavelength: $365 \mathrm{~nm}$. (b) Fluorescence image of the unground sample 3 under $365 \mathrm{~nm}$ UV light. (c) Fluorescence image of the ground sample 3 under $365 \mathrm{~nm}$ UV light. (d) Fluorescence image of the ground sample 3 after treatment with dichloromethane under $365 \mathrm{~nm}$ UV light.

when the ground sample was exposed to dichloromethane vapor for $1 \mathrm{~min}$, the sharp and intense peaks reappeared, indicative of the recovery of the crystalline nature. As presented

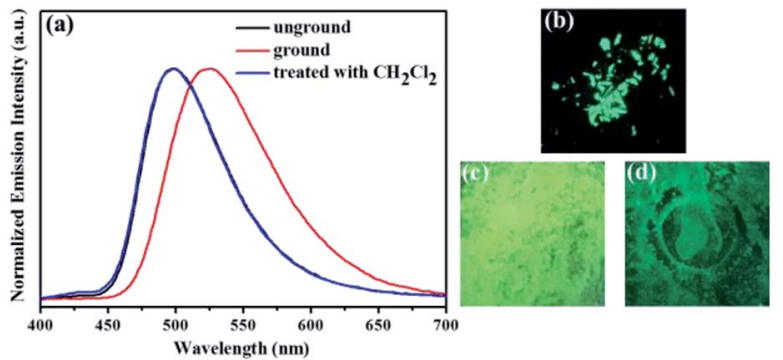

Fig. 8 (a) PL spectra of solid sample 4 at different conditions. Excitation wavelength: $365 \mathrm{~nm}$. (b) Fluorescence image of the unground sample 4 under $365 \mathrm{~nm}$ UV light. (c) Fluorescence image of the ground sample 4 under $365 \mathrm{~nm}$ UV light. (d) Fluorescence image of the ground sample 4 after treatment with dichloromethane under $365 \mathrm{~nm}$ UV light.
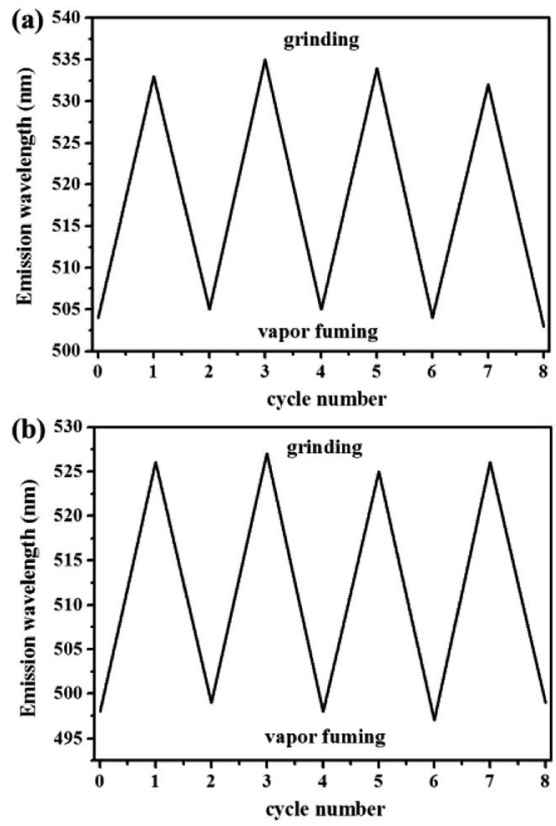

Fig. 9 (a) Repetitive experiment of mechanofluorochromic effect for compound 3. (b) Repetitive experiment of mechanofluorochromic effect for compound 4 .

in Fig. 11, the structural transition of the powder sample of compound $\mathbf{3}$ or $\mathbf{4}$ was similar to that of $\mathbf{1}$ or $\mathbf{2}$. Based on the above mentioned analysis, the powder XRD results demonstrated that the interesting mechanochromic fluorescence characteristics of compounds 1, 2, 3 and 4 were ascribed to the switchable morphology transition between the crystalline state and the amorphous state.

In conclusion, in this work, four triphenylamine or carbazole-based benzothiadiazole fluorescent molecules were successfully synthesized. The compounds 1, 2, 3 and $\mathbf{4}$ belonged to the highly solid-state emissive donor-acceptor (D-A) type luminescent molecules. It is noteworthy that the four D-A type luminogens exhibited high-contrast mechanofluorochromic characteristics. Furthermore, the reversibility of their mechanochromic phenomena is good. The results of powder XRD 

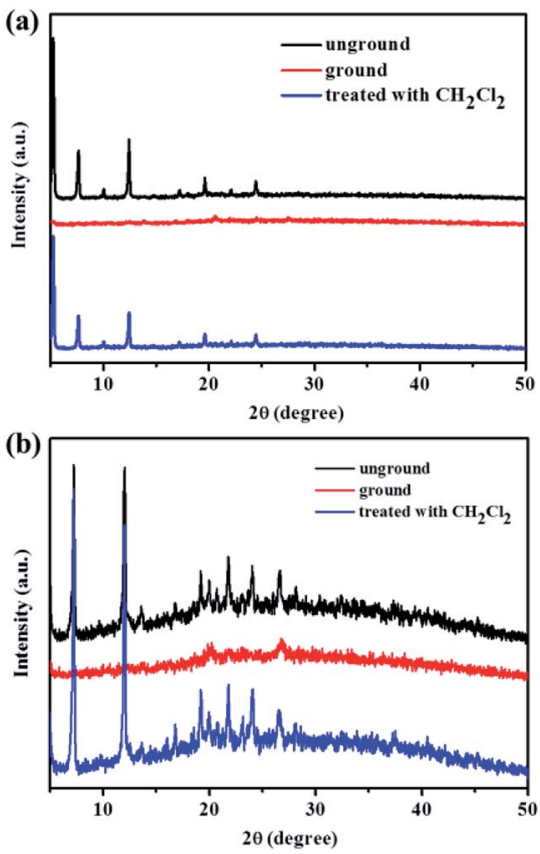

Fig. 10 (a) Powder XRD patterns of compound 1 in different solid states. (b) Powder XRD patterns of compound 2 in different solid states.
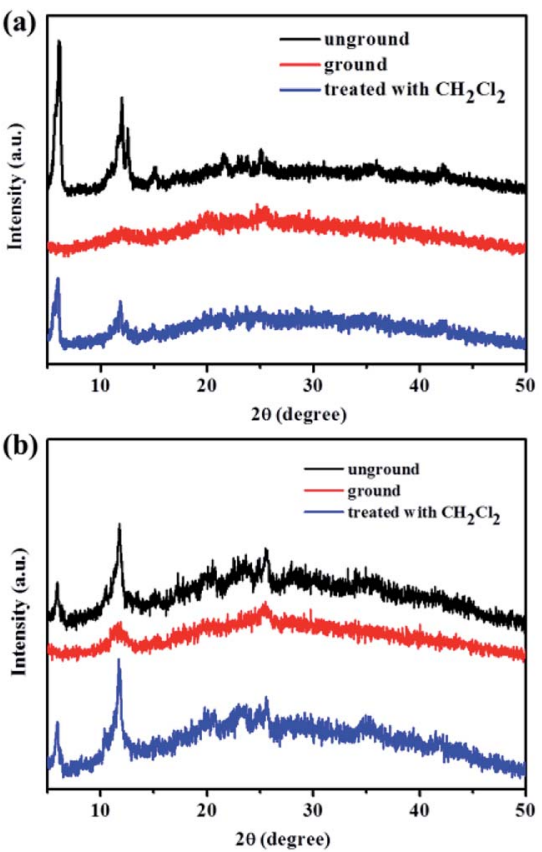

Fig. 11 (a) Powder XRD patterns of compound 3 in different solid states. (b) Powder XRD patterns of compound 4 in different solid states.

experiments confirmed that this switchable morphology transformation is responsible for the reversible mechanochromic fluorescence characteristics of $\mathbf{1}, 2,3$ and 4 . This work is valuable for designing high-contrast mechanochromic materials involving red light-emitting feature.

\section{Conflicts of interest}

There are no conflicts to declare.

\section{Acknowledgements}

The authors are grateful for the financial support from the National Natural Science Foundation of China (21867011, 51563011) and the Project of the Science Fund of Jiangxi Education Office (GJJ170672).

\section{Notes and references}

1 C. Dou, L. Han, S. Zhao, H. Zhang and Y. Wang, J. Phys. Chem. Lett., 2011, 2, 666-670.

2 N. V. Lakshmi, D. Mandal, S. Ghosh and E. Prasad, Chem.Eur. J., 2014, 20, 9002-9011.

3 B. Xu, Z. Chi, X. Zhang, H. Li, C. Chen, S. Liu, Y. Zhang and J. Xu, Chem. Commun., 2011, 47, 11080-11082.

4 K.-P. Wang, Y. Chen and Y. Liu, Chem. Commun., 2015, 51, 1647-1649.

5 X. Zhu, R. Liu, Y. Li, H. Huang, Q. Wang, D. Wang, X. Zhu, S. Liu and H. Zhu, Chem. Commun., 2014, 50, 12951-12954.

6 X. Cui, J. Zhao, Y. Zhou, J. Ma and Y. Zhao, J. Am. Chem. Soc., 2014, 136, 9256-9259.

7 Z. Chen, G. Liu, S. Pu and S. H. Liu, Dyes Pigm., 2017, 143, 409-415.

8 Z. Chen, D. Wu, X. Han, Y. Nie, J. Yin, G.-A. Yu and S. H. Liu, RSC Adv., 2014, 4, 63985-63988.

9 Y. Dong, B. Xu, J. Zhang, X. Tan, L. Wang, J. Chen, H. Lv, S. Wen, B. Li, L. Ye, B. Zou and W. Tian, Angew. Chem., Int. Ed., 2012, 51, 10782-10785.

10 W. Chen, S. Wang, G. Yang, S. Chen, K. Ye, Z. Hu, Z. Zhang and Y. Wang, J. Phys. Chem. C, 2016, 120, 587-597.

11 J. Wei, B. Liang, X. Cheng, Z. Zhang, H. Zhang and Y. Wang, RSC Adv., 2015, 5, 71903-71910.

12 F. Zhao, C. Fan, Z. Chen, G. Liu and S. Pu, RSC Adv., 2017, 7, 43845-43848.

13 J. Zhang, Z. Chen, L. Yang, F. Hu, G.-A. Yu, J. Yin and S.-H. Liu, Dyes Pigm., 2017, 136, 168-174.

14 Z. Chi, X. Zhang, B. Xu, X. Zhou, C. Ma, Y. Zhang, S. Liu and J. Xu, Chem. Soc. Rev., 2012, 41, 3878-3896.

15 P. Xue, J. Ding, P. Wang and R. Lu, J. Mater. Chem. C, 2016, 4, 6688-6706.

16 R. Tan, S. Wang, H. Lan and S. Xiao, Curr. Org. Chem., 2017, 21, 236-248.

17 H. Ito, T. Saito, N. Oshima, N. Kitamura, S. Ishizaka, Y. Hinatsu, M. Wakeshima, M. Kato, K. Tsuge and M. Sawamura, J. Am. Chem. Soc., 2008, 130, 10044-10045.

18 Z. Chen, J. Zhang, M. Song, J. Yin, G.-A. Yu and S. H. Liu, Chem. Commun., 2015, 51, 326-329.

19 Z. Chen, J. Liang, Y. Nie, X. Xu, G.-A. Yu, J. Yin and S. H. Liu, Dalton Trans., 2015, 44, 17473-17477.

20 T. Hu, B. Yao, X. Chen, W. Li, Z. Song, A. Qin, J. Z. Sun and B. Z. Tang, Chem. Commun., 2015, 51, 8849-8852.

21 S. Xue, X. Qiu, Q. Sun and W. Yang, J. Mater. Chem. C, 2016, 4, 1568-1578. 
22 F. Zhao, Z. Chen, G. Liu, C. Fan and S. Pu, Tetrahedron Lett., 2018, 59, 836-840.

23 B. Xu, J. He, Y. Mu, Q. Zhu, S. Wu, Y. Wang, Y. Zhang, C. Jin, C. Lo, Z. Chi, A. Lien, S. Liu and J. Xu, Chem. Sci., 2015, 6, 3236-3241.

24 M. Mitani, S. Ogata, S. Yamane, M. Yoshio, M. Hasegawa and T. Kato, J. Mater. Chem. C, 2016, 4, 2752-2760.

25 Y. Hong, J. W. Y. Lam and B. Z. Tang, Chem. Soc. Rev., 2011, 40, 5361-5388.

26 J. Mei, Y. Hong, J. W. Y. Lam, A. Qin, Y. Tang and B. Z. Tang, Adv. Mater., 2014, 26, 5429-5479.

27 J. Mei, N. L. C. Leung, R. T. K. Kwok, J. W. Y. Lam and B. Z. Tang, Chem. Rev., 2015, 115, 11718-11940.

28 Z. Chen, G. Liu, S. Pu and S. H. Liu, Dyes Pigm., 2018, 152, 5459.

29 Z. Chen, G. Liu, S. Pu and S. H. Liu, Dyes Pigm., 2018, 159, 499-505.

30 Y. Qi, Y. Wang, Y. Yu, Z. Liu, Y. Zhang, G. Du and Y. Qi, RSC Adv., 2016, 6, 33755-33762.

31 G.-G. Shan, H.-B. Li, H.-T. Cao, D.-X. Zhu, P. Li, Z.-M. Su and Y. Liao, Chem. Commun., 2012, 48, 2000-2002.

32 Z. Chen, D. Wu, X. Han, J. Liang, J. Yin, G.-A. Yu and S. H. Liu, Chem. Commun., 2014, 50, 11033-11035.

33 J. Ni, Y.-G. Wang, H.-H. Wang, L. Xu, Y.-Q. Zhao, Y.-Z. Pan and J.-J. Zhang, Dalton Trans., 2014, 43, 352-360.

34 J. Ni, X. Zhang, Y.-H. Wu, L.-Y. Zhang and Z.-N. Chen, Chem.Eur. J., 2011, 17, 1171-1183.

35 Z. Chen, Z. Li, F. Hu, G.-A. Yu, J. Yin and S. H. Liu, Dyes Pigm., 2016, 125, 169-178.
36 F. Ciardelli, G. Ruggeri and A. Pucci, Chem. Soc. Rev., 2013, 42, 857-870.

37 S. Ito, T. Taguchi, T. Yamada, T. Ubukata, Y. Yamaguchi and M. Asami, RSC Adv., 2017, 7, 16953-16962.

38 S. Ito, T. Yamada, T. Taguchi, Y. Yamaguchi and M. Asami, Chem.-Asian J., 2016, 11, 1963-1970.

39 X. Song, H. Yu, X. Yan, Y. Zhang, Y. Miao, K. Ye and Y. Wang, Dalton Trans., 2018, 47, 6146-6155.

40 C. Dou, D. Chen, J. Iqbal, Y. Yuan, H. Zhang and Y. Wang, Langmuir, 2011, 27, 6323-6329.

41 K. C. Naeem, K. Neenu and V. C. Nair, ACS Omega, 2017, 2, 9118-9126.

42 D. Wu, B. Fang, M. Zhang, W. Du, J. Zhang, X. Tian, Q. Zhang, H. Zhou, J. Wu and Y. Tian, Dyes Pigm., 2018, 159, 142-150.

43 J. Sun, X. Lv, P. Wang, Y. Zhang, Y. Dai, Q. Wu, M. Ouyang and C. Zhang, J. Mater. Chem. C, 2014, 2, 5365-5371.

44 B. Wex and B. R. Kaafarani, J. Mater. Chem. C, 2017, 5, 86228653.

45 X. Gan, Y. Wang, X. Ge, W. Li, X. Zhang, W. Zhu, H. Zhou, J. Wu and Y. Tian, Dyes Pigm., 2015, 120, 65-73.

46 J. Liang, Z. Chen, L. Xu, J. Wang, J. Yin, G.-A. Yu, Z.-N. Chen and S. H. Liu, J. Mater. Chem. C, 2014, 2, 2243-2250.

47 F. Zhao, Z. Chen, C. Fan, G. Liu and S. Pu, Dyes Pigm., 2019, 164, 390-397.

48 Y. Han, H.-T. Cao, H.-Z. Sun, G.-G. Shan, Y. Wu, Z.-M. Su and Y. Liao, J. Mater. Chem. C, 2015, 3, 2341-2349. 